\title{
Anti-emetic activity of four species of Genus Cassia in chicks
}

\author{
Salman Ahmed ${ }^{1}$,Affan Zahid $^{2}$, Safia Abidi $^{3}$, Sadia Meer $^{4}$ \\ ${ }^{1-4}$ (Department of Pharmacognosy, Faculty of Pharmacy, University of Karachi, Karachi - 75270, Pakistan)
}

\begin{abstract}
The anti-emetic activity of the leaves methanolic extracts of Cassia angustifolia Vahl., Cassia holosericea Fresen., Cassia italica Miller. Lam. ex F.W. Ander and Cassia purpurea Roxb., was evaluated in young chicks. Emesis was induced by copper sulfate $(50 \mathrm{mg} / \mathrm{kg}$ ) and the extracts were tested at the dose of $150 \mathrm{mg} / \mathrm{kg}$ orally. All the extracts decreased significantly the number of retching $(p<0.05$ and $p<0.01)$ when compared with standard chlorpromazine.
\end{abstract}

Keywords: Anti-emetic activity, Cassia angustifolia, Cassia italica, Cassia purpurea, Chicks.

\section{INTRODUCTION}

Emesis and nausea are thought to be the protective reflexes which serve to get rid the toxic substances from stomach and intestine and prevent their further ingestion. Emesis is a complex process which comprise of three phases pre - ejection phase (gastric relaxation and retro-peristalsis), retching (rhythmic action of respiratory muscles preceding vomiting and consisting of contraction of abdominal, intercostals and diaphragmatic muscles against a closed glottis) and ejection (intense contraction of the abdominal muscles and relaxation of the upper esophageal sphincter) which is due to the interaction of gastrointestinal system (visceral afferents from the GI tract), the vestibular system, and the various parts of the brain like Chemoreceptor trigger zone (CTZ) [1-3]. It is controlled by two separate centers of brain stem: the vomiting center and chemoreceptor trigger zone[4]. Pregnancy, obstruction, peptic ulcer, drug toxicity, myocardial infarction, renal failure, and hepatitis are the conditions which result emesis. Administration of drugs particularly cancer chemotherapeutic agents potentiate emesis [5].

The genus Cassia Linn. comprises of 600 species of flowering plants in the family Caesalpiniaceae, occurring mostly in the tropics and sub-tropics, and is widely distributed in America, Brazil, China, East Africa, India, Malaysia, Mauritius, Mexico, Pakistan, Srilanka, South Africa and West Indies. It is the largest genus in the family Caesalpiniaceae having a wide range of habits[6,7]. In Pakistan 26 species of Cassia are reported [8]. Caesalpiniaceae represents approximateley $11 \%$ of the known legume flora[9] with about 152 genera and 2800 species, mostly distributed in tropical and subtropical region of the world[10]. In Pakistan it is represented by 17genera and 54 species[8]. Cassia species are well known in folk medicine for their laxative and purgative uses. They are also widely used for treating skin diseases such as ringworm, scabies, eczema and wounds[11-13]. In traditional system of medicine (Unani medicine / Greeko-Arab medicine) different parts of Cassia angustifolia Vahl., Cassia holosericea Fresen., Cassia italica Miller. Lam. ex F.W. Ander and Cassia purpurea Roxb., are reported as laxative ${ }^{7}$, vermifuge, resolvent, blood purifier, carminative, digestive, diaphoretic[1416], astringent, antipyretic, diuretic[17], anti-diabetic and anthelmintic[18]. The chemical literature survey of these plants revealed the presence of glycosides[19-22], sterols[23,24] flavonoids, saponins[25] and alkaloids[26,27].

Although these plants have been used in GI disorders in traditional medicine[16,21,28-33], there is no scientific report as their anti-emetic effect in the literature. In the present study we report the anti-emetic effect of the methanol extracts of the leaves of four Cassia species.

\section{MATERIALS AND METHODS}

2.1. Chemicals: Copper sulphate was purchased from Scharlau Chemie S.A. Barcelona, Spain. Chlorpromazine was purchased from ICN, USA. Dimethyl sulfoxide (DMSO) and methanol were purchased from Merck, Darmstadt, Germany.

2.2. Collection of plant materials: Leaves of all four species were collected from Karachi, Pakistan during the month of May 2011 and voucher specimen was kept in Department of Pharmacognosy for future reference.

2.3. Preparation of the extracts: Leaves were dried in shade at room temperature for 15 days. After that all the leaves were chopped and ground. All plant material were soaked in methanol for two days at room temperature then filtered through filter paper. These extracts were then concentrated under vacuum at $40^{\circ} \mathrm{C}$. As a result four methanolic extracts were obtained which were used for anti-emetic activity.

2.4. Animals: Young male chicks, 4 days of age, weighing from $32-52 \mathrm{~g}$ were taken from local market. After 24 hrs fasting, the anti-emetic activity was evaluated. All experiments performed on laboratory animals in this study followed the "Principle of Laboratory Animal Care and the Guide for the use of laboratory animals" (NIH Publication No. 85.23, Rev. 1985).

2.5. Antiemetic activity[34,35]:The anti-emetic activity was determined by calculating the mean decreased in number of retching reflexes in contrast with those of control as described in literature. The four days old chicks were divided into six 
groups of six chicks in each group. Group 1 served as the control and was treated with $5 \mathrm{ml} 0.9 \%$ normal saline/kg body weight. Group 2 was treated with $150 \mathrm{mg}$ chlorpromazine/kg body weight orally. Groups 3, 4, 5 and 6 were treated with $150 \mathrm{mg}$ extract $/ \mathrm{kg}$ b.w., orally. Each chick was set aside for 10 minutes to stabilize in a large beaker. Chlorpromazine and the extracts were dissolved in $0.9 \%$ saline containing $5 \%$ DMSO and $1 \%$ tween 80 and administered abdominally at a dose of $150 \mathrm{mg} / \mathrm{kg}$ to the test animal. After 10 minutes copper sulfate was administered orally at $50 \mathrm{mg} / \mathrm{kg}$ to each chick, then the number of retching (an emetic action without emitting gastric material) was observed during the next 10 minutes.

The percent inhibition was calculated by the following formula:

Inhibition $(\%)=[(\mathrm{A}-\mathrm{B}) / \mathrm{A}] \times 100$

Where $\mathrm{A}=$ Frequency of retching in control group

$\mathrm{B}=$ Frequency of retching in test groups

2.6.Statistical analysis used: Values for anti-emetic activity were expressed as mean \pm S.E.M. The statistical significance of the difference was determined by an unpaired student's $t$-test and differences between means were considered to be significant when $p<0.05$ and highly significant when $p<0.01$.

\section{RESULTS AND DISCUSSION}

The anti-emetic activity of the methanol extracts of four Cassia species was determined by calculating the mean decrease in number of retching reflexes in comparison with control. The results are shown in Table.

Table. The anti-emetic effect of the methanol extracts of four Cassia species on copper sulfate induced emesis in chicks.

\begin{tabular}{|l|l|l|}
\hline Drug & $\begin{array}{l}\text { Number of Retches } \\
\text { (Mean } \pm \text { SEM) }\end{array}$ & $\begin{array}{l}\text { Inhibition } \\
(\mathbf{\%})\end{array}$ \\
\hline Control & $70.10 \pm 3.28$ & - \\
\hline CZ & $45.40 \pm 3.11^{*}$ & 35.23 \\
\hline CA & $14.5 \pm 3.18^{*}$ & 79.31 \\
\hline CH & $40.66 \pm 4.10^{*}$ & 41.99 \\
\hline CI & $2.75 \pm 1.02^{*}$ & 96.07 \\
\hline CP & $3.85 \pm 1.11^{*}$ & 94.50 \\
\hline
\end{tabular}

$\mathrm{CZ}=$ Chlorpromazine, $\mathrm{CA}=$ Cassia angustifolia, $\mathrm{CH}=$ Cassia holosericea, $\mathrm{CI}=$ Cassia italica, $\mathrm{CP}=$ Cassia purpurea, $\mathrm{N}=6$, Dose $=150 \mathrm{mg} / \mathrm{kg}$ p.o., $p^{*}<0.05$ and $p * *<0.01$ are Significantly different from control value where $*=$ Significant and $* *=$ Highly significant using unpaired student's $t$-test.

In all the four extracts Cassia italica showed highest (96.07\%) inhibition of retches as the chicks showed 2.75 mean numbers of retches where as Cassia holosericea showed lowest (41.99\%) inhibition of retches with 40.66 mean numbers of retches. Cassia purpurea showed $94.50 \%$ inhibition and 3.85 mean numbers of retches where as Cassia angustifolia showed $79.31 \%$ inhibition of retches with 14.5 mean numbers of retches. The standard drug chlorpromazine inhibited $35.23 \%$ retches and showed 45.40 mean numbers of retches. The mean number of retches in control was 70.10 (Fig a \& b). 

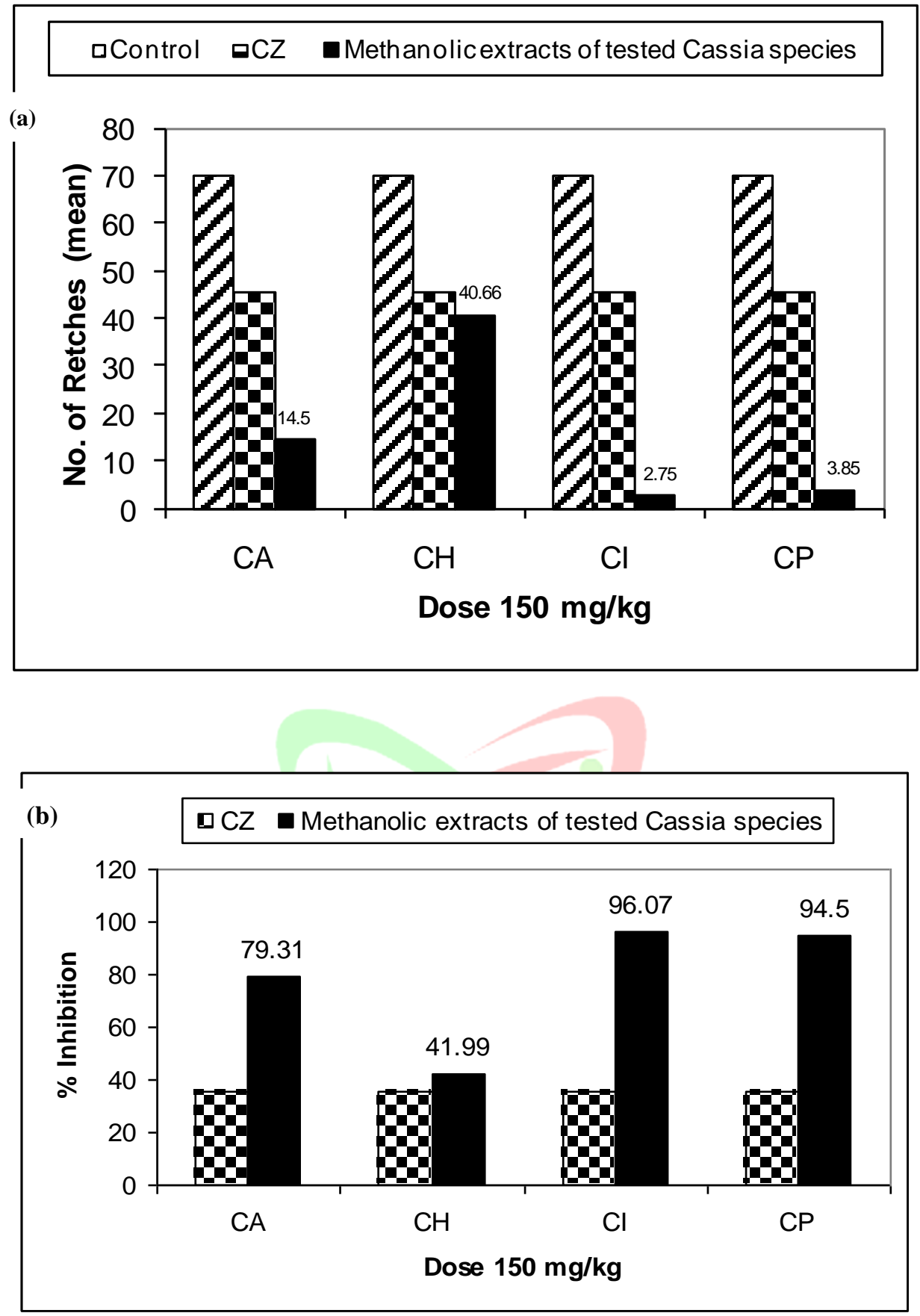

Figure(a,b): Comparison of anti-emetic activity of tested Cassia species against Chlorpromazine as an anti-emetic effect in chicks (a) Graphical presentation of Mean number of retches versus dose $150 \mathrm{mg} / \mathrm{kg}$ (b) Graphical presentation of $\%$ inhibition of retches versus dose $150 \mathrm{mg} / \mathrm{kg}$

Anti-emetics reduce the hyper reactive vomiting reflex, at the level of vomiting center or CTZ or on the vestibular nuclei via the labyrinthine apparatus in the inner ear (central action) and also directly by the G.I. irritation [36]. Chlorpromazine is a phenothiazine and acting by inhibition of CTZ via a dopaminergic blocking action; primarily effective for drug induced emesis as well as nausea and vomiting associated with surgery, anesthesia, radiation, carcinoma, chronic renal failure and severe infections $[4,36]$.

Generally chicks $[34,35,37]$ and frogs $[38-40]$ are used as test subjects to determine the antiemetic potential of plant extracts and natural products. Copper sulfate induced retching in chicks is a useful animal model used in screening for antiemetic effects of plant extracts and compounds and was adopted for this anti-emetic study because this model mimic acute emesis seen in man and serves as a useful model for evaluating the involvement of the brain in the observed anti-emetic effects of the extracts[41]. This bioassay is also useful in screening for anti-emetic activity as it is an easy method in short time and the observation is only by counting the retching[34,35]. 
The anti-emetic activity of the methanol extracts of Cassia angustifolia, Cassia holosericea, Cassia italica and Cassia purpurea showed that these extracts have anti-emetic effect in young chicks. All extracts significantly $(p<0.05$ and $p$ $<0.01)$ suppressed the frequency of copper sulfate-induced retching. Therefore from the results it is clear that all these extracts have protective effects against copper sulfate induced retching in young chicks, possibly by peripheral action as the oral copper sulfate induces emesis by peripheral action through excitation of visceral afferent nerve fibers of the GIT[42]. It has also been established that the peripheral 5- $\mathrm{HT}_{4}$ play an important role in copper sulfate induced emesis[43,44].

Although the results are significant and comparable with reference drug chlorpromazine but the mode of action and responsible compounds are not known. However, flavonoids are reported to possess anti-emetic activity[40] and flavonoids are reported from the leaves methanolic extracts of Cassia angustifolia[45], Cassia italica[46] and Cassia purpurea[47]. So, antiemetic effect may be due to the presence of these flavonoids. Therefore these results need to be verified in other experimental models and the compound(s) related activity is required to further specify the responsible anti-emetic phytochemicals.

Traditionally all these plants are used in dyspepsia, abdominal cramps and GI disorders [16,21,28-33]. Therefore, this study also validates the traditional use of these plants in GI disorders.

\section{CONCLUSION}

The present investigation justifies the anti-emetic potential of studied Cassia species. However, further study is required regarding responsible anti-emetic compound.

\section{REFERENCES}

1. ASHP, Therapeutic guidelines on the pharmacologic management of nausea and vomiting in adult and paediatric patients receiving chemotherapy or radiation therapy or undergoing surgery, American Journal of Health-System Pharmacy, 56(8), 1999, 729-764.

2. J.P. Pankaj,Prokinetic agents, antiemetics, and agents used in irritable bowl syndrome In: Gilman, A.G., L.S. Goodman (Eds.), The Pharmacological Basis of Therapeutics, 10 ${ }^{\text {th }}$ edition, (New York: The McGraw-Hill Companies, Inc., Medical Publishing Division, 2001),1029.

3. T.J. Gan, T. Meyer, C.C. Apfel, F. Chung, P. J. Davis, S. Eubanks, A. Kovac, B. K. Philip, D. I. Sessler, J. Temo, M. R. Tramèr and M. Watcha, Consensus guidelines for managing post operative nausea and vomiting, Anesthesia \& Analgesia, 97(1), 2003, 62-71.

4. L. R. John, C.R. Peter and W. Brain,Drugs and Gastrointestinal disease" In:Lecture notes on Clinical Pharmacology, Fourth (Four Dragons) edition, (Oxford: Blackwell Scientific Publications, 1992) 189-92.

5. A.L. Kovac, Prevention and post operative nausea and vomiting. Drugs, 59(2), 2000, 213-43.

6. E.N.U. Okpon, Morphological notes on the genus Cassia. I. Notes Royal Botanic Gardens Edinburgh, 29, 1969, 185 -195 .

7. P.M. Mazumder, V. Percha, M. Farswan and A. Upaganlawar, Cassia: A Wonder Gift to Medical Sciences, International Journal of Community Pharmacy, 1, 2008, 16 - 38.

8. S.I . Ali, Caesalpniaceae In: Flora of Pakistan. E. Nasir and S.I. Ali (eds.), 54: (Karachi: Department of Botany, 1973) 1-47.

9. J.H. Kirkbride, Phylogeny and classification of Pakistan Legumes. Pakistan Journal of Botany, 18, 1986, $287-299$.

10. J.C. Willis, A dictionary of the flowering plants and frens, Eight edition revised by H.K. Airyshow. (Cambridge University press, 1973).

11. F. R. Irvine, Woody Plants of Ghana” (London: Oxford University Press,1961) 285.

12. T. V. Benjamin and A. Lamikanra, Investigation of Cassia alata, a plant used in Nigeria in the treatment of skin diseases, Pharmaceutical Biology, (2-3), 1981, 93-96.

13. A.A. Eluojoba, A.T. Abere and S. A. Adelusi, Laxatives activities of Cassia pods sourced from Nigeria, Nig. J. Nat. Prod. Med. 3, 1999, $51-53$.

14. M.N. Ghani,Khazinatul Advia, Vol III, (Lucknow: Naval Kishore Press,1913) 330-333.

15. R. Lubhaya, Goswami Bayanul Advia, Vol II, (Delhi: Goswami Pharmacy, Qasim Jan Street, 1975$) 147$.

16. M.H. Awan, Kitab-ul-Mufridat Almaruf be Khawas-ul-Advia, (Lahore: Sheikh Ghulam Ali and Sons Ltd Publishers, 1984) 372.

17. E.G. Marta, G.A. Bongiovanni, L. Palacio, C.O. Nuñez and J.J. Cantero, Medicinal plants from the "Sierra de Comechingones", Argentina, Journal of Ethnopharmacology, 107(3), 2006, 324 - 341.

18. A.H. Memon, F.M.A. Rind, M.G.H. Laghari, U.R. Mughal, N. Memon and R.A. Gilal et al Common folk medicinal and ethnomedicinal uses of thirty medicinal plants of Districts Dadu and Jamshoro, Sindh, Pakistan, Sindh University Research Journal (Science Series), 40, 2008, 89-108.

19. S. Malhotra and K. Misra, A New Anthraquinone from Cassia sophera Heartwood, Planta Medica, 46(4), 1982, 247-291.

20. S.C. Jain, R. Jain, R.A. Sharma \& F. Capasso, Pharmacological investigation of Cassia italica. Journal of Ethnopharmacology, 58(2), 1997, 135-142. 
21. C. Deachapunya, W. Thongsaard and S. Poonyachoti, Barakol suppresses norepinephrine-Induced inhibition of spontaneous longitudinal smooth muscle contractions in isolated rat small intestine. Journal of Ethnopharmacology, 101(1-3), 2005, 227-232.

22. H.M. Suresh, B.C. Hatapakki, S.J. Shivkumar, C.S. Hallikeri, B.M. Swamy and V.K. Chandur, Laxative activity of Cassia auriculata pods in rats, Journal of Natural Remedies, 7(1), 2007, 150-54.

23. M.H. Kazmi, A. Malik, S. Hameed, N. Akhtar and S.N. Ali, An anthraquinone derivative from Cassia italica, Phytochemistry, 36(3), 1994, 761-763.

24. Y. Zhao, J-P. Liu, D. Lu and P-Y. Li, A novel cycloartane triterpene glycoside from the seeds of Cassia sophera L., Naural Product Research, 21(6), 2007, 494-499.

25. S.C. Jain, R.A. Sharma and R. Jain, Sennosides in Cassia italica in vivo and in vitro, Fitoterapia, 67(1), $1996,82$.

26. S. Khalid and G. Shahid, The fatty acids of indigenous resources for possibleindustrial applications: Part XVIII. The fatty acid composition of the fixed oils of Leucaena leucocephala and Cassia holosericea. Pakistan Journal of Scientific and Industrial Research, 32(9), 1989, 643-645.

27. M.K. Rai, Ethnomedicinal studies of Chindwara district (M.P.) I. Plants used in stomach disorders. Indian Medicine, 2,1989, 1-5.

28. Chopra, R.N., S.L. Nayar and I.C.Chopra, Glossary of Indian Medicinal Plants, Vol. I. (New Delhi: CSIR,1956) 197.

29. K. Usmanghani, A. Saeed and M. T. Alam. (Eds.) Indusyunic medicine, (University of Karachi, Pakistan: B.C.C. and T Press,1997) 146.

30. M.O. Amamoto, S. Shimura, Y. Itoh, T. Ohsaka andM. Egawa, Anti-obesity effects of lipase inhibitor CT-II, an extract from edible herbs, Nomame Herba, on rats fed a high-fat diet, International Journal of Obesity, 24(6), 2000, 758-64.

31. V.Agarwal and M. Bajpai, Pharmacognostical and biological studies on Senna and its products: An overview, International Journal of Pharmacy and Biological Sciences, 1(2),2010,1-10.

32. M.C. Nisha and S. Rajeshkumar, Survey of crude drugs from Coimbatore city. Indian Journal of Natural Products and Resources, 1(3), 2010, 376-383.

33. Shukla A.N., S. Srivastava \& A.K.S. Rawat, An ethnobotanical study of medicinal plants of Rewa district, Mahya Pradesh. Indian Journal of Traditional Knowledge, 9(1),2010, 191-202.

34. Y. Akita, Y. Yang. T. Kawai, K. Kinoshita, K. Koyama and K. Takahashi, New assay method for surveying antiemetic compounds from natural sources, Natural Product. Sciences, 4(2), 1998, 72-77.

35. Y. Yang, K. Kinoshita, K. Koyama, K. Takahashi, T. Tai and Y. Nunoura, K. Watanabe .Anti-emetic principles of Pogostemon cabin (Blanco) Benth, Phytomedicine, 6(2), 1999, 89-93.

36. T. M . Roger and E.G. Sandra, Emetics and Antiemetics, In: Pharmacology drug therapy and nursing considerations , $3^{\text {rd }}$ edition, (Philadelphia: J. B. Lippincott Company, 1990) 520-26.

37. M. Eda, Y. Hayashi, K. Kinoshita, K. Koyama, K. Takahashi and K. Akutu, Anti-emetic principles of water extract of Brazilian Propolis. Pharmaceutical Biology,43(2), 2005, 184-88.

38. T. Kawai, K. Kinoshita, K. Koyama and K. Takahashi, Anti-emetic principles of Magnolia obovata and Zingiber officinale, Planta Medica, 60(1), 1994,17-20.

39. T. Tai, Y. Akita, K. Kinoshita, K. Koyama, K. Takahashi and K.Watanabe, Anti-Emetic Principles of Poria cocos, Planta Medica, 61(6), 1995, 527-530.

40. K. Kinoshita, T. Kawai, T. Imaizumi, Y. Akita, K. Koyama and K. Takahashi, Anti-emetic principles of Inula linariaefolia flowers and Forsythia suspense fruits. Phytomedicine, 3(1), 1996, 51-58.

41. A. Y. Tijani, S. E. Okhale, F. E. Oga, S. Z. Tags, O. A. Salawu, and B. A. Chindo, Anti-emetic activity of Grewia lasiodiscus root extract and fractions, African Journal of Biotechnology, 7(17), 2008, 3011-3016.

42. W.C. Bowman and M.J. Rand, Textbook of pharmacology, (Oxford: Blackwell Scientific Publication, 1980).

43. P. Bhandari and P.L.R. Andrews, Preliminary evidence for the involvement of the putative 5-HT $\mathrm{H}_{4}$ receptor in zacopride- and copper sulfate-induced vomiting in the ferret, European Journal of Pharmacology, 204(3), 1991, 273-280.

44. H. Fukui, M. Yamamoto, S. Sasaki and S. Sato, Possible involvement of peripheral 5-HT4 receptors in copper sulfate-induced vomiting in dogs. European Journal of Pharmacology, 257(1-2), 1994, 47-52.

45. M. Goppel and G. Franz. Stability Control of Senna Leaves and Senna extracts. Planta Medica, 70(5), 2004, 432436.

46. A. A. Nassr-Allah, A. M. Aboul-Enein, K. M. Aboul-Enein, D. A. Lightfoot, A. Cocchetto and H. A. El-Shemy, Anti-cancer and anti-oxidant activity of some Egyptian medicinal plants, Journal of Medicinal Plants Research, 3(10), 2009, 799-808.

47. A. Rahman, M. Mizanur Rahman, Md. M. I. Sheik, M. M. Rahman, S. M. Shadli and M. F. Alam, Free radical scavenging activity and phenolic content of Cassia sophera L, African Journal of Biotechnology, 7(10),2008, 15911593. 